\title{
Comparison of morphology, phenotypes and function between cultured human IL-4-DC and IFN-DC
}

\author{
ZHILIANG JIN $^{1^{*}}$, JING FAN $^{2 *}$, YAJUAN ZHANG ${ }^{3}$, YONGXIANG YI ${ }^{2}$, \\ LILI WANG $^{2}$, DANDAN YIN ${ }^{2}$, TAO DENG ${ }^{1}$ and WEI YE ${ }^{2,4}$
}

\begin{abstract}
${ }^{1}$ Department of Gastroenterology, Renmin Hospital of Wuhan University, Wuhan, Hubei 430000; ${ }^{2}$ Cancer Research and Biotherapy Center, The Second Hospital of Nanjing, Medical School, Southeast University, Nanjing, Jiangsu; ${ }^{3}$ Health Management Center, Danyang People's Hospital, Zhenjiang, Jiangsu; ${ }^{4}$ Liver Disease Department,

The Second Hospital of Nanjing, Medical School, Southeast University, Nanjing, Jiangsu 210003, P.R. China
\end{abstract}

Received March 16, 2017; Accepted September 5, 2017

DOI: $10.3892 / \mathrm{mmr} .2017 .7581$

\begin{abstract}
Dendritic cells (DCs) as professional antigen presenting cells, are important in the initiation of the primary immune response. The present study compared the morphology, phenotypes and function between monocyte-derived human DCs produced from a conventional culturing system containing granulocyte-macrophage colony-stimulating factor (GM-CSF) and IL-4 (IL-4-DC) and DCs generated by the stimulation of GM-CSF and interferon (IFN)- $\alpha$ (IFN-DC). When compared with IL-4-DC in morphology, IFN-DC contained more organelles, including endoplasmic reticulum and myelin figures, whereas mature (m)IL-4-DC contained more vacuoles in the cells. The spikes of IFN-DC were shorter and thicker. The expression of phenotypes between immature IFN-DC
\end{abstract}

Correspondence to: Dr Tao Deng, Department of Gastroenterology, Renmin Hospital of Wuhan University, 99 Zhangzhidong Road, Wuhan, Hubei 430000, P.R. China

E-mail: yanhuaxuhj@163.com

Dr Wei Ye, Cancer Research and Biotherapy Center, The Second Hospital of Nanjing, Medical School, Southeast University, 1-1 ZhongFu Road, Gulou, Nanjing, Jiangsu 210003, P.R. China E-mail: yeweiseu@163.com

*Contributed equally

Abbreviations: APC, antigen-presenting cells; CLTA-4, cytotoxic $\mathrm{T}$ lymphocyte-associated antigen-4; DCs, dendritic cells; FACS, fluorescence-activated cell sorting; FBS, fetal bovine serum; GM-CSF, granulocyte macrophage-colony stimulating factor; $\mathrm{HCV}$, hepatitis $\mathrm{C}$ virus; IFN- $\alpha$, interferon- $\alpha$; IL-4, interleukin- 4 ; mAbs, monoclonal antibodies; MHC, major histocompatibility complex; PBMCs, peripheral blood mononuclear cells; poly I:C, polyinosinic: polycytidylic acid; STAT6, signal transducer and activator of transcription 6; Th1, T helper cell 1; Th2, T helper cell 2; Th17, $\mathrm{T}$ helper cell 17 ; TNF- $\alpha$, tumor necrosis factor- $\alpha$

Key words: cross-present, dendritic cell, IFN- $\alpha$, immunotherapy, vaccine and IL-4-DC were diverse. Following maturation with tumor necrosis factor- $\alpha$, IFN-DC and IL-4-DC upregulated the expression of cluster of differentiation (CD) 11c and CD83. Conversely, immature IFN-DC and IL-4-DC secreted few inflammatory cytokines including interleukin (IL)-18, IL-23, IL-12p70, IL-1 $\beta$ and anti-inflammatory IL-10. Following maturation, large amounts of the cytokines were secreted by these two DCs and mIFN-DC secreted more cytokines compared with mIL-4-DC in general. Furthermore, immature IFN-DC and IL-4-DC loaded with cytomegalovirus (CMV)-pp65 protein were unable to induce the priming of $\mathrm{T}$ cells, as evaluated by the intracellular staining with IFN- $\gamma$. Notably, mature DCs exhibited the ability to present CMV-pp65 protein and activate $\mathrm{T}$ cells. The mIFN-DC activated a greater proportion of autologous $\mathrm{CD} 4^{+} \mathrm{T}$ cells $(0.91$ vs. $0.31 \%, \mathrm{P}<0.001)$ and $\mathrm{CD} 8^{+}$ $\mathrm{T}$ cells $(0.90$ vs. $0.48 \%, \mathrm{P}<0.001)$ to secret IFN $-\gamma$ compared with mIL-4-DC. The results suggested that the morphology, phenotypes and cytokine secretion of IFN-DC and IL-4-DC were diverse. The mIFN-DC were more effective in priming and cross-priming T cells when compared with IL-4-DC.

\section{Introduction}

Dendritic cells (DCs) are the most potent professional antigen-presenting cells (APC). As we know, DCs can capture, process and present antigens to $\mathrm{T}$ cells and play a key role in the induction of Ag-specific immune responses to viruses, bacteria, allergens and tumor antigens (1). DCs have been commonly used in cancer immunotherapy in recent years. However, there are only a low frequency of DCs $(<2 \%)$ in human peripheral blood mononuclear cells (PBMCs) and peripheral organs. Moreover, this population cannot be expanded in vitro $(2,3)$. As a result, DCs separated from human PBMCs or organs directly have been seldom applied to clinical trials. Instead the monocyte-derived DCs have been widely studied in clinical trials as these DCs subsets could sustain most of DCs function and be cultured much easier compared with the DCs in vivo.

Traditionally, investigators use granulocyte-macrophage colony-stimulating factor (GM-CSF) and interleukin (IL)-4 to stimulate monocyte to differentiate into IL-4-DC. Reports have showed that IL-4-DC derived from both rat bone marrow and 
PBMCs can present and cross-present antigens in vitro $(4,5)$. Moreover, IL-4-DC has been utilized in immunotherapy of cancer and HIV infection. Recent studies have showed that interferon (IFN)- $\alpha$ is an important cytokine belonging to the type I IFN family, which is endowed with potent antiviral, antitumor, and immunoregulatory activities (6). Paquette et al (7) firstly revealed that IFN- $\alpha$ and GM-CSF could induce the differentiation of monocytes into IFN-DC. Some reports have showed that IFN-DC could be more effective than IL-4 DC to induce cluster of differentiation $(\mathrm{CD}) 4^{+} \mathrm{T}$ cell and $\mathrm{CD} 8^{+} \mathrm{T}$ cell response in different models (8-11). Lapenta et al (8) found that IFN-DC loaded with HIV-1 antigen could induce the cross-priming of $\mathrm{CD}^{+} \mathrm{T}$ cells against HIV in the hu-PBL-SCID mouse more effectively than IL-4 DC. Moreover, IFN-DC could cross-present low amounts of nonstructural-3 protein (NS3) of hepatitis $\mathrm{C}$ virus (HCV) and activate $\mathrm{HCV}$-specific $\mathrm{CD}^{+} \mathrm{T}$ cells efficiently (12). However, the mechanisms of the effect of IFN-DC remain to be determined and the details of the phenotypes and function of these DCs still need to be explored.

In this study, we cultured both IFN-DC and IL-4-DC and investigated the difference between these two DCs subsets in the aspects of cell morphology, cell phenotypes and secretion of cytokines. The function of IFN-DC and IL-4-DC in the presentation and cross-presentation of virus antigen also was explored.

\section{Materials and methods}

Human blood donors and preparation of PBMCs. PBMCs were obtained from healthy volunteers. Written informed consents were obtained from all donors in accordance with the Declaration of Helsinki. PBMCs were isolated using Ficoll density gradient centrifugation (TBD, Tianjin, China) and cultured in RPMI-1640 medium containing 10\% fetal bovine serum (FBS; Gibco; Thermo Fisher Scientific, Inc., Waltham, MA, USA), $100 \mathrm{U} / \mathrm{ml}$ penicillin and $100 \mathrm{ng} / \mathrm{ml}$ streptomycin. All studies were approved by the Institutional Review Board (IRB) of the Second Hospital of Nanjing.

Cell separation and DC generation. Monocytes were isolated by immunomagnetic cell sorting (MACS Cell Isolation kits; Miltenyi Biotec, Bergisch Gladbach, Germany). Positive selected $\mathrm{CD}_{14}{ }^{+}$cells were analyzed by flow cytometry. Purity of the $\mathrm{CD}_{14}{ }^{+}$cells was $>98 \%$. Purified $\mathrm{CD} 14^{+}$monocytes were cultured in RPMI-1640 medium containing $10 \%$ FBS, $100 \mathrm{U} / \mathrm{ml}$ penicillin and $100 \mathrm{ng} / \mathrm{ml}$ streptomycin at the concentration of $1 \times 10^{6} / \mathrm{ml}$, supplemented with $1,000 \mathrm{U} / \mathrm{ml}$ IFN- $\alpha 2 b$ (Anterferon; Anhui, China) and $40 \mathrm{ng} / \mathrm{ml}$ GM-CSF for IFN-DC or $20 \mathrm{ng} / \mathrm{ml} \mathrm{IL-4} \mathrm{(both} \mathrm{from} \mathrm{R \& D} \mathrm{Systems,}$ Minneapolis, MN, USA) and $40 \mathrm{ng} / \mathrm{ml} \mathrm{GM-CSF}$ for IL-4-DC. The cells were incubated at $37^{\circ} \mathrm{C}$ and $5 \% \mathrm{CO}_{2}$ for 5 days. Half of the supernatants were moved and fresh cytokines and mediums were added every 3 days. DCs were matured by adding $20 \mathrm{ng} / \mathrm{ml}$ tumor necrosis factor- $\alpha$ (TNF- $\alpha$; R\&D Systems) and culturing for another $48 \mathrm{~h}$.

Electron microscopy. For ultrastructural analysis, electron microscopy was performed using standard procedures (13). Briefly, all samples were washed and fixed in $2.5 \%$ glutaraldehyde in $85 \mathrm{mM}$ phosphate buffer ( $\mathrm{pH}$ 7.2) and post-fixed in $\mathrm{OsO}_{4}$ solution. Then the cells were dehydrated in graded alcohol solutions and embedded in epoxy resin. Mature IFN-DC and IL-4-DC were examined at $80 \mathrm{kV}$ under Hitachi electron microscope H-7650.

Immunophenotypic analysis. Cultured DCs were washed and resuspended in PBS containing 1\% FBS and incubated with a series of monoclonal antibodies (mAbs) including anti-HLA-DR, CD11c, CD80, CD83 and CD86 (BD Pharmingen, San Diego, CA, USA) for $30 \mathrm{~min}$ at $4^{\circ} \mathrm{C}$. All mAbs were conjugated with PerCp-, APC, or PE-. Then the samples were analyzed by a fluorescence-activated cell sorting (FACS)Canto II flow cytometer (BD Biosciences, San Jose, CA, USA). Data were collected with BD FACSDiva software and analyzed with TreeStar FlowJo software.

Cytokine secretion analysis. Supernatants from immature and mature DCs were harvested at day 5 and day 7 separately. Cytokine concentrations of supernatants were determined by ELISA. IL-10, IL-18, IL-23, IL-1 $\beta$ and IL-12p70 were measured using the ELISA kits according to the manufacturer's protocol (Multi Sciences, Hangzhou, China).

Analysis of antigen-specific $T$ cells by intracellular IFN- $\gamma$ staining. For antigen presentation assays, cultured DCs from heathy donors were seeded into a 96-well round-bottomed plate at $1 \times 10^{5}$ cells/well. Then, $10 \mu \mathrm{g} / \mathrm{ml}$ cytomegalovirus (CMV)-pp65 protein (Miltenyi Biotec) was added into the specified wells. After $2 \mathrm{~h}, \mathrm{CD}^{+}$and $\mathrm{CD}^{+} \mathrm{T}$ lymphocytes obtained by immunomagnetic cells sorting as described above were co-cultured with CMV-pp65 protein loaded DCs at the DCs/T lymphocytes ratio of 1:10 in RPMI-1640 containing $10 \%$ human $\mathrm{AB}$ serum, $100 \mathrm{U} / \mathrm{ml}$ penicillin and $100 \mathrm{ng} / \mathrm{ml}$ streptomycin for $12 \mathrm{~h}$ at $37^{\circ} \mathrm{C}$. Then GolgiPlug protein transport inhibitor (BD Pharmingen) was added into the wells. After another $6 \mathrm{~h}$, cells were harvested and washed in washing buffer and stained with live/dead fixable dead cell staining (Invitrogen; Thermo Fisher Scientific, Inc.), FITC-conjugated anti-CD4, PE-conjugated anti-CD8 and PerCp-conjugated anti-CD3 (BD Pharmingen) for $30 \mathrm{~min}$ at $4^{\circ} \mathrm{C}$. After washing, the cells were fixed and permeabilized by the Cytofix/Cytoperm solution (BD Pharmingen) for $20 \mathrm{~min}$ at $4^{\circ} \mathrm{C}$. Then the cells were rewashed in perm washing buffer and stained with APC-conjugated anti-IFN- $\gamma$ (BD Pharmingen) for $30 \mathrm{~min}$ at $4^{\circ} \mathrm{C}$. At last, the cells were analyzed on a BD Canto II flow cytometer.

Statistics. Data were expressed as means \pm SEMs and analyzed with SPSS V20.0 software. The statistical significance of differences was determined by the Student's t-test and one-way ANOVA. A value of $\mathrm{P}<0.05$ was considered to indicate a statistically significant result.

\section{Results}

Morphological analysis of IFN-DC and IL-4-DC. In the past few years, some reports have showed that IFN-DC and IL-4-DC had some similar characteristics of DCs in morphology (14). However, McRae et al (15) showed that IL-4-DC contained more and longer spikes than IFN-DC. So we explored the 
A

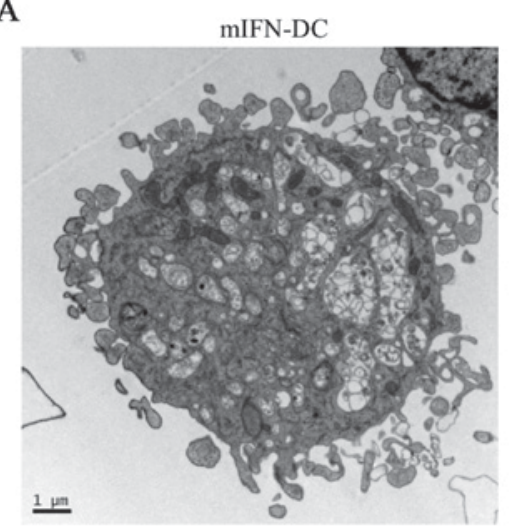

B

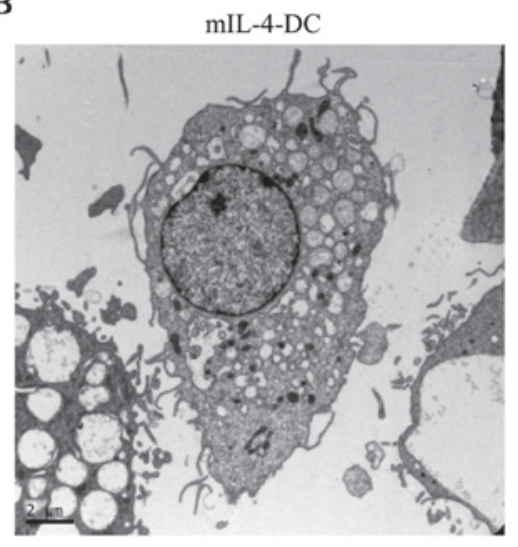

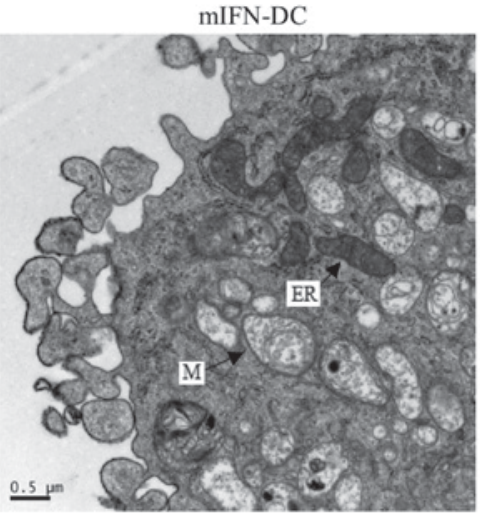

mIL-4-DC

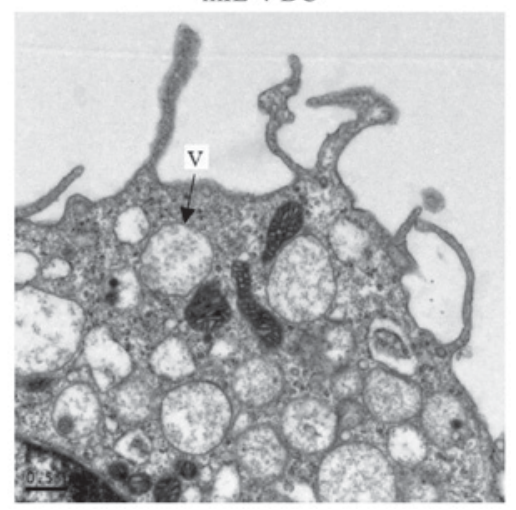

$\mathrm{C}$
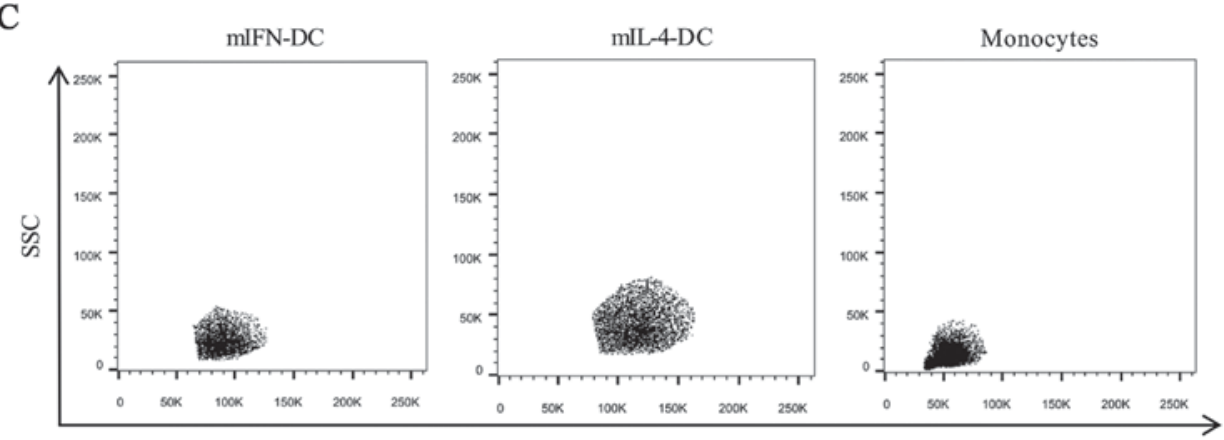

FSC

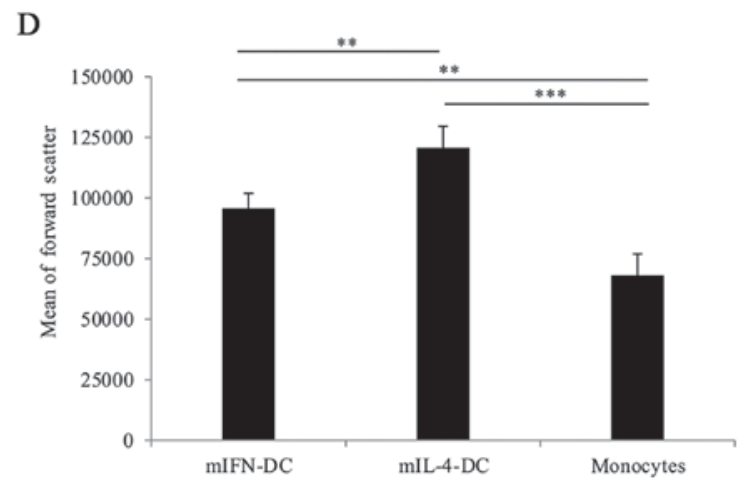

Figure 1. Morphology of mIFN-DC and mIL-4-DC derived from CD14+ monocytes. Mature DCs were produced in vitro by culturing monocytes with IFN- $\alpha$ and GM-CSF or GM-CSF and IL-4. Then TNF- $\alpha$ was used to promote the maturation. The scanning electron micoscopy and FACS analysis were conducted to compare the morphologies of these two DCs. (A and B) Scanning electron micoscopy photographs of the integral and the local of mIFN-DC and mIL-4-DC, respectively. (C) FACS analysis of mIFN-DC, mIL-4-DC and monocytes. Nonviable cells were eliminated from analysis. (D) Forward scatter values, generated by FACS, revealed the sizes of mIFN-DC, mIL-4-DC and monocytes. Results were representative of 5 independent experiments. Statistical analysis comparing the size of different DCs and monocytes was performed with the independent-sample t-test $\left({ }^{* *} \mathrm{P}<0.01,{ }^{* * *} \mathrm{P}<0.001\right)$. DCs, dendritic cells; IFN, interferon; TNF- $\alpha$, tumor necrosis factor- $\alpha$; IL, interleukin; FACS, fluorescence-activated cell sorting; CD, cluster of differentiation; $m$, mature; M, myelin figures; ER, endoplasmic reticulum; V, vacuoles; FSC, forward scatter; SSC, side scatter. 
A

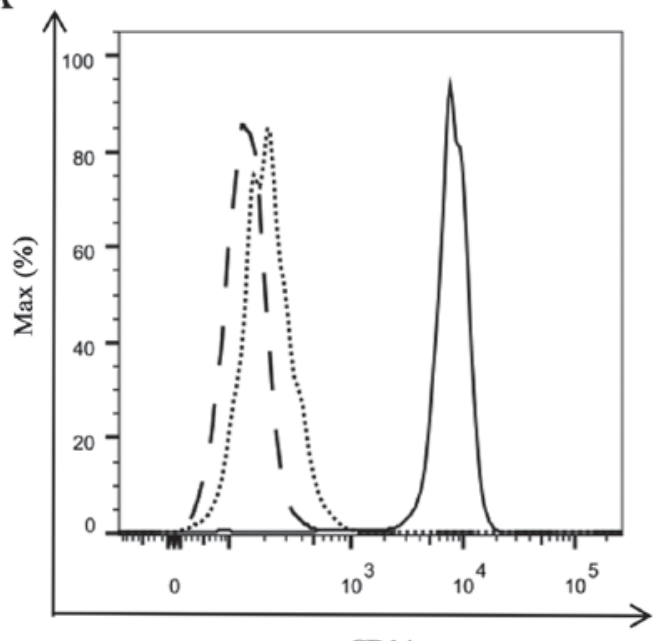

CD14

\section{B}

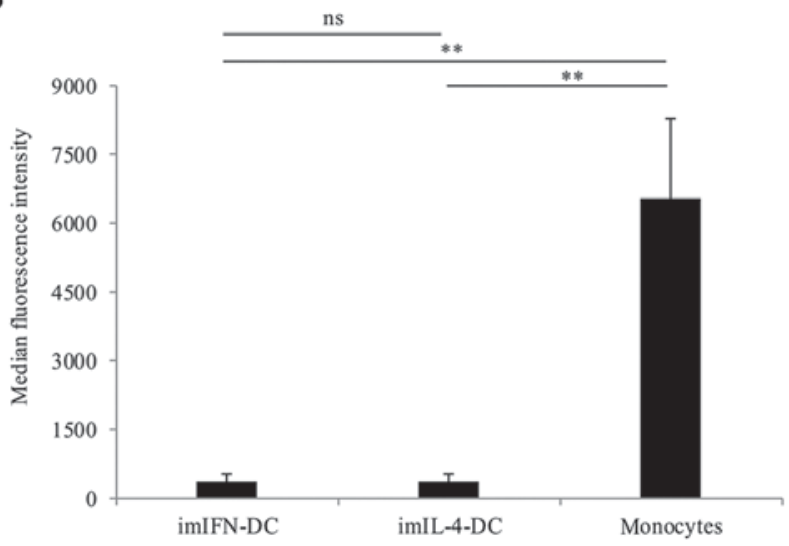

Figure 2. Expression of CD14 of IFN-DC, IL-4-DC and monocytes. (A) Representative FACS figure of the CD14 expression on the surface of immature DCs and monocytes. Solid line represents monocytes, dotted line represents imIFN-DC, dashed line represents imIL-4-DC. (B) MFI of CD14 detected by FACS. Results were representative of 5 independent experiments. Statistical analysis was performed with the independent-sample t-tes $\left({ }^{* *} \mathrm{P}<0.01\right) . \mathrm{CD}$, cluster of differentiation; IFN, interferon; IL, interleukin; DCs, dendritic cells; FACS, fluorescence-activated cell sorting; MFI, median fluorescence intensity; im, immature.

details of these two DCs subsets in morphology. We cultured purified $\mathrm{CD}^{+} 4^{+}$monocytes added with GM-CSF and IFN- $\alpha$ or GM-CSF and IL-4 to get immature IFN-DC (imIFN-DC) and immature IL-4 DC (imIL-4-DC), respectively.

TNF- $\alpha$, LPS, CD40L and polyinosinic:polycytidylic acid (poly I:C) was reported to be used to promote the mature of DCs in vitro $(16,17)$. However, disable DCs could be induced by the stimulation of LPS or poly I:C (17). So TNF- $\alpha$ was used to induce imIFN-DC and imIL-4-DC to differentiate into mature IFN-DC (mIFN-DC) and mature IL-4-DC (mIL-4-DC). Then morphological differences between mIFN-DC and mIL-4-DC were compared by scanning electron micoscopy. Fig. 1A and B showed that the size of mIL-4-DC was larger than mIFN-DC. Meanwhile, the outcomes of FACS analyses were consistent with the electron micoscopy results and both mIFN-DC and mIL-4-DC appeared to be larger in size compared with the monocytes $(\mathrm{P}<0.01)$ (Fig. $1 \mathrm{C}$ and $\mathrm{D}$ ). Furthermore, although both mIFN-DC and mIL-4-DC obtained numerous of pseudopodia, the sharp of the spikes of mIFN-DC was short and thick while the mIL4-DC had long and thin spikes (Fig. 1A and B). On the other hand, we observed that mIFN-DC contained more organelles, like endoplasmic reticulum, and myelin figures than mIL-4-DC while mIL-4-DC contained more vacuoles in the cells.

Comparison of the cell phenotypes between IFN-DC and $I L-4-D C$. To investigate the difference of the cell phenotypes between IFN-DC and IL-4-DC, we detected the expression of CD14 on the surface of imIFN-DC and imIL-4-DC firstly. Compared with the monocytes, both of imIFN-DC and imIL-4-DC expressed much lower CD14 as shown in Fig. 2. And there was no obvious difference between imIFN-DC and imIL-4-DC for the expression of CD14 ( $>>0.05)$.

Then, we analyzed the expression of major histocompatibility complex (MHC) I molecules HLA-DR, mDC marker CD11c, costimulatory molecules CD80 and CD86 and mature marker CD83 of IFN-DC and IL-4-DC. The results showed that the expression of HLA-DR, CD11c, CD80, CD83 and CD86 were up-regulated on both imIFN-DC and imIL-4-DC compared with monocytes (Fig. 3A). After the maturation of DCs stimulated by TNF- $\alpha$, we detected the expression of these phenotypic markers again. As illustrated in Fig. 3B and C, mIFN-DC expressed higher HLA-DR, CD11c, CD83 and CD86 compared with imIFN-DC $(\mathrm{P}<0.001)$, and mIL-4-DC expressed higher CD11c, CD80 and CD83 compared with imIL-4-DC $(\mathrm{P}<0.001)$. Compared with mIL-4-DC, HLA-DR and CD86 were expressed higher on the surface of mIFN-DC $(\mathrm{P}<0.001)$ while the expression of CD80 and CD83 had no obvious difference $(\mathrm{P}>0.05)$. Intriguingly, mIFN-DC expressed lower CD11c compared with mIL-4-DC $(\mathrm{P}<0.01)$.

Cytokines secreted by IFN-DC and IL-4-DC. A series of cytokines, such as IL-12, IL-27 and IL-10, could be secreted by DCs and these cytokines played a key role in immune response (18-20). So, we evaluated the cytokines secretion in the supernatants from DCs cultures. Supernatants were quantified for IL-10, IL-18, IL-23, IL-1 $\beta$ and IL-12p70 by ELISA. When comparing between imIFN-DC and imIL-4-DC, there was no obvious difference for the secretion of cytokines IL-10, IL-18 and IL-23 (P>0.05) (Fig. 4A-C). However, IL-1 $\beta$ could be secreted more effectively by imIFN-DC than imIL-4-DC $(\mathrm{P}<0.05)$ (Fig. 4D). The secretion of IL-12p70 could not be detected in neither imIFN-DC group nor imIL-4-DC group (Fig. 4E). In response to TNF- $\alpha$, these two mature DCs could secrete amounts of IL-12p70. Meanwhile, mIFN-DC could secrete more IL-12p70, IL10, IL-18 and IL-1 $\beta$ compared with mIL-4-DC $(\mathrm{P}<0.05)$. In contrast, there was no difference between mIFN-DC and mIL-4-DC for the secretion of IL-23 $(\mathrm{P}>0.05)$.

Comparison of the presentation ability between IFN-DC and IL-4-DC to activate CMV-pp65 specific T lymphocytes. To investigate the presentation ability of IFN-DC and IL-4-DC, the immature and mature IFN-DC or IL-4-DC loaded with the CMV-pp65 protein were cultured with autologous $\mathrm{CD} 4^{+}$ and $\mathrm{CD} 8^{+} \mathrm{T}$ cells, respectively. Then the percentages of IFN $-\gamma^{+} \mathrm{CD} 4^{+}$and IFN- $\gamma^{+} \mathrm{CD} 8^{+} \mathrm{T}$ lymphocytes were detected by flow cytometry intracellular staining (Fig. $5 \mathrm{~A}$ and B). The 
A
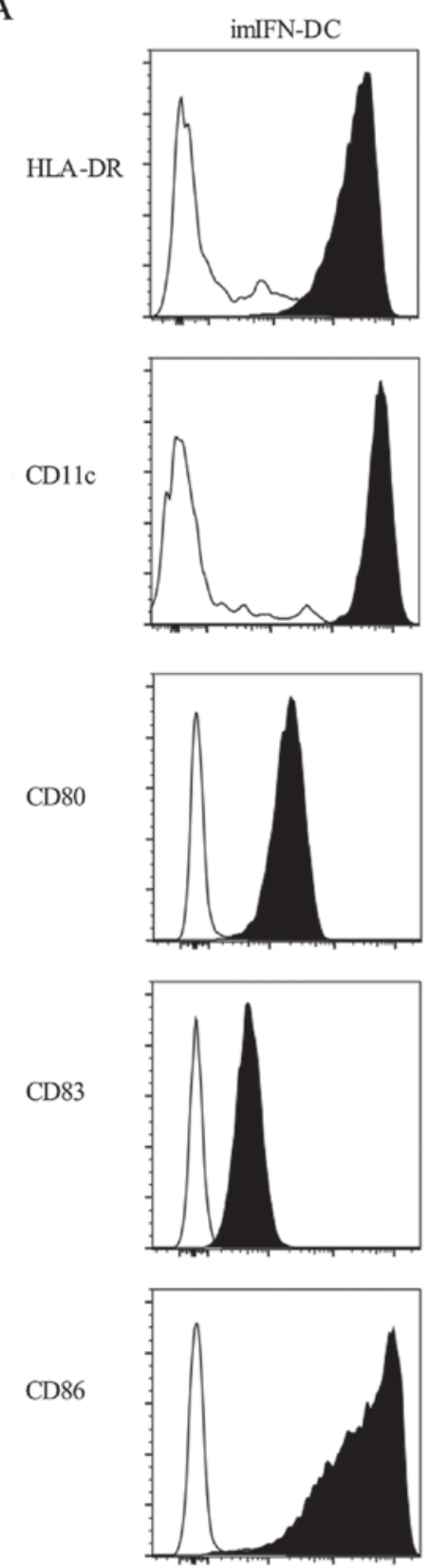
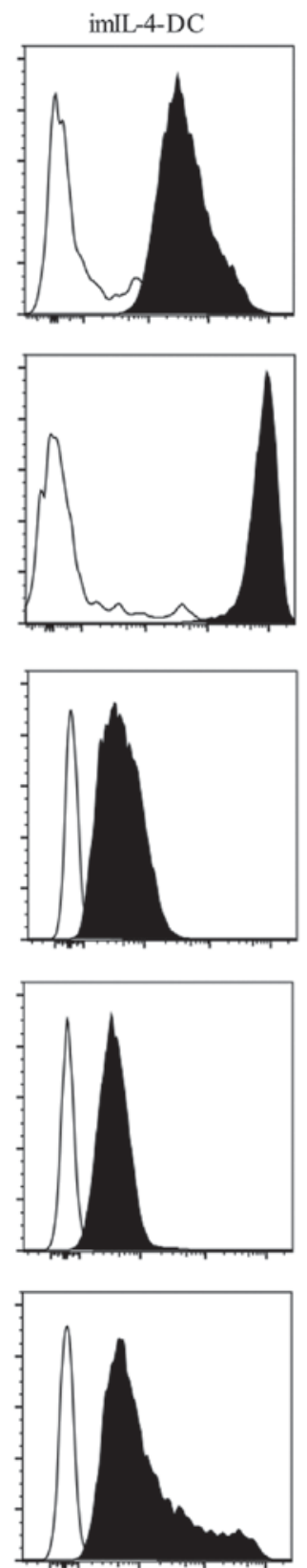

results showed that there was no obvious difference for the percentages of IFN $-\gamma^{+} \mathrm{CD} 4^{+}$and IFN $-\gamma^{+} \mathrm{CD} 8^{+} \mathrm{T}$ lymphocytes between imIFN-DC group, imIL-4-DC and negative control group ( $\mathrm{P}>0.05$ ) (Fig. 5C and D). After maturation, both of mIFN-DC and mIL-4 could induce the secretion of IFN- $\gamma$ of $\mathrm{CD}^{+}$and $\mathrm{CD} 8^{+} \mathrm{T}$ lymphocytes compared with the negative control $(\mathrm{P}<0.05)$. Notably, when compared with the mIL-4-DC, mIFN-DC loaded with CMV-pp65 protein could activate higher proportion of autologous $\mathrm{CD} 4^{+} \mathrm{T}$ cells $(0.91 \%$ vs. $0.31 \%, \mathrm{P}<0.001)$ and $\mathrm{CD} 8^{+} \mathrm{T}$ cells $(0.90 \%$ vs. $0.48 \%$, $\mathrm{P}<0.001)$ to secret IFN $-\gamma$ (Fig. 5C and D).

\section{Discussion}

Monocytes play diverse roles in human immunity, such as clearance of senescent cells, pathogen killing and immune regulation $(21,22)$. In vivo, monocytes can differentiate into

B

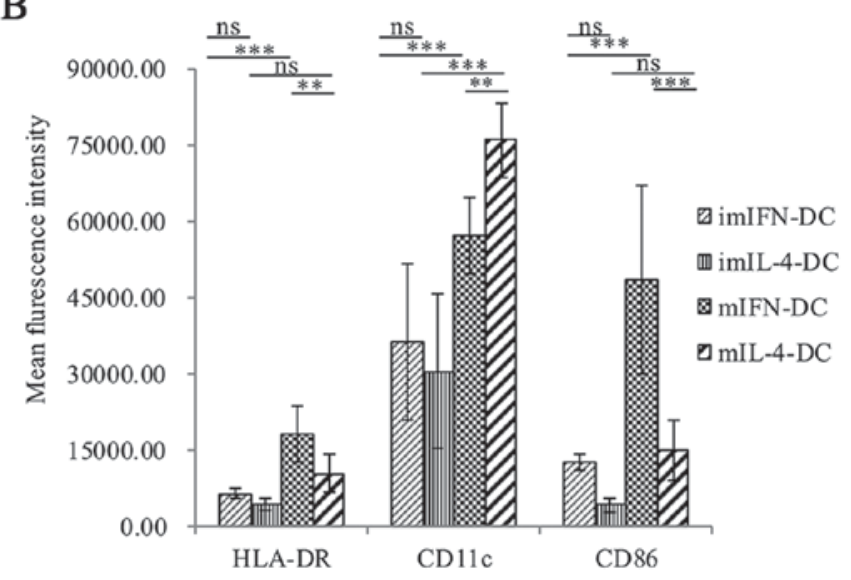

c

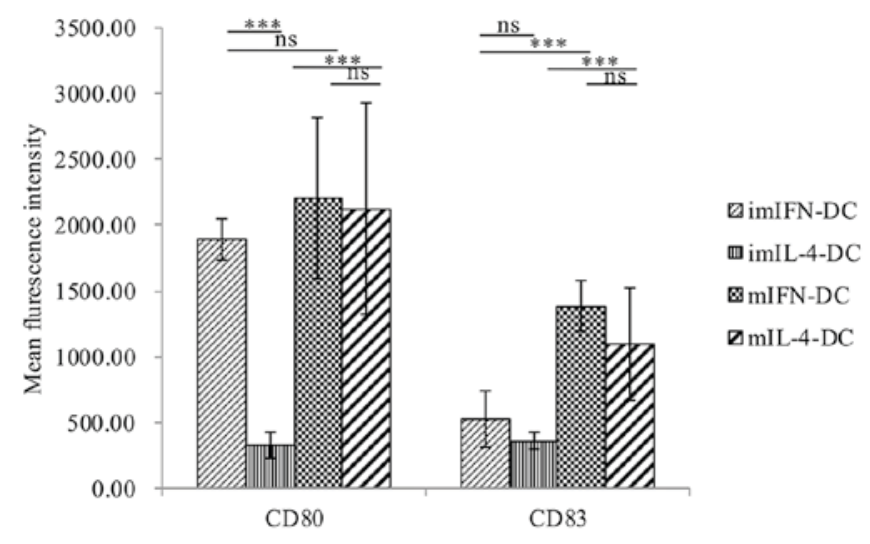

Figure 3. Phenotypes expressed on the surface of IFN-DC and IL-4-DC. (A) Both imIFN-DC and imIL-4-DC expressed HLA-DR, CD11c, CD80, CD83, CD86. Empty histograms showed the background staining with monocytes, and solid histograms represented specific staining of the indicated cell surface markers. (B and C) Median fluorescence intensity of HLA-DR, CD11c, CD80, CD83 and CD86 expressed by imIFN-DC, imIL-4-DC, mIFN-DC, and mIL-4-DC. Results were represented as means \pm SEMs obtained from 5 independent experiments. Statistical analysis was performed with one-way ANOVA $\left({ }^{* *} \mathrm{P}<0.01,{ }^{* * *} \mathrm{P}<0.001\right)$. CD , cluster of differentiation; IFN, interferon; IL, interleukin; DCs, dendritic cells; m, mature; im, immature.

macrophages. In vitro, monocytes from separated human PBMCs can be induced to differentiate into DC after the stimulation of numerous cytokines (23). In the past, IL-4 combined with GM-CSF were widely used to induce the differentiation of monocytes $(17,24)$. Wang et al (25) discovered that IL-4-DC could express more phenotypes of mature cells than GM-CSF DC developed by culturing monocytes with GM-CSF alone. In recent years, many researchers have focused on the exploit of IFN-DC developed by culturing monocytes with GM-CSF and IFN- $\alpha$ as this DCs subset could be more effective than IL-4-DC in the aspect of antigen cross-presentation (26). Moreover, some studies revealed that the antigen presentation of IL-4-DC relied on the signal transducer and activator of transcription 6 (STAT6) while IFN-DC was not, suggesting that these two DCs have different presenting ways $(25,27,28)$. Although IFN-DC and IL-4-DC have been studied for several years, the details 
A

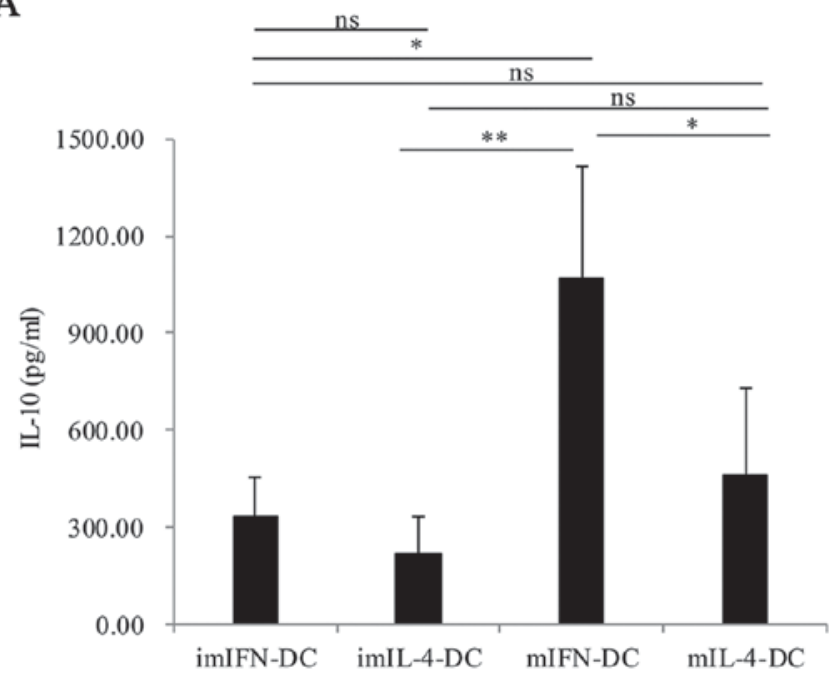

C

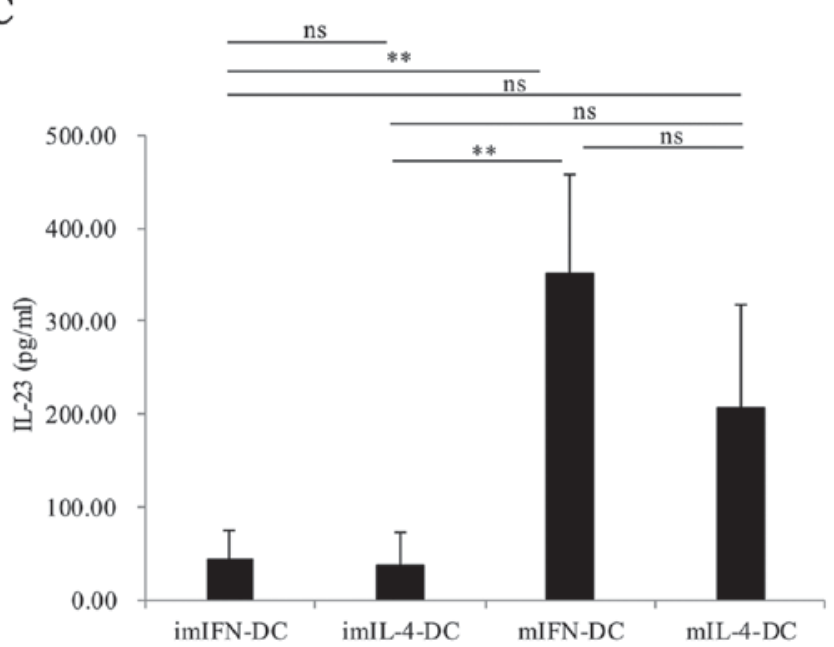

B

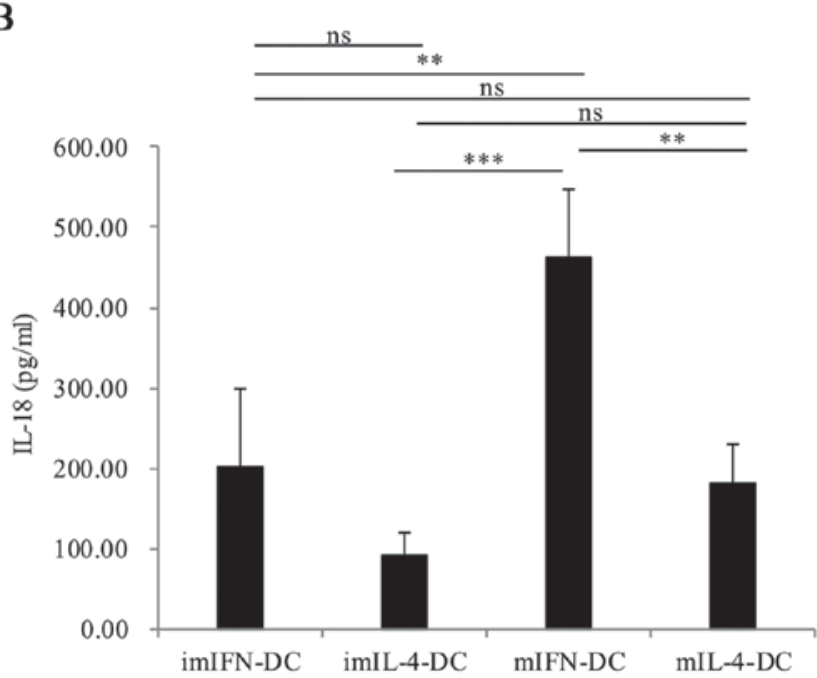

D

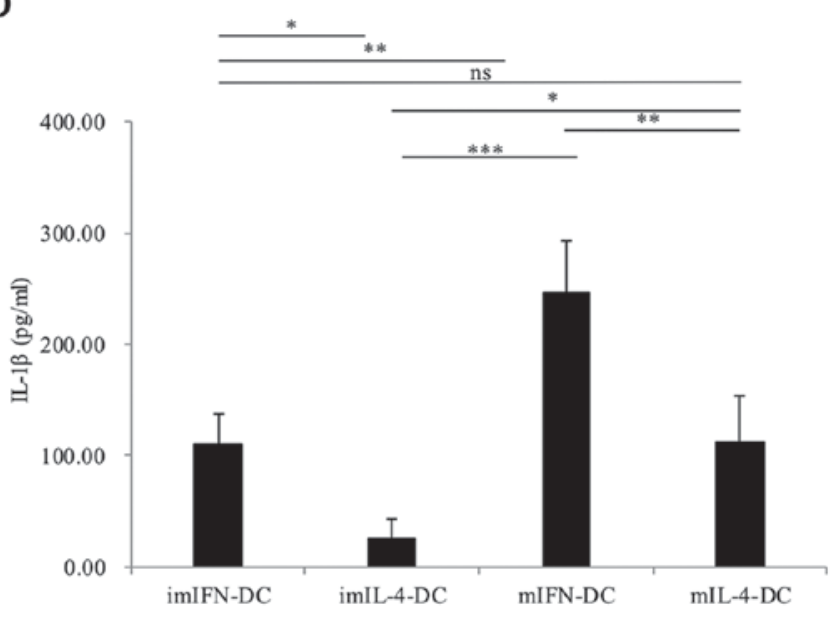

$\mathrm{E}$

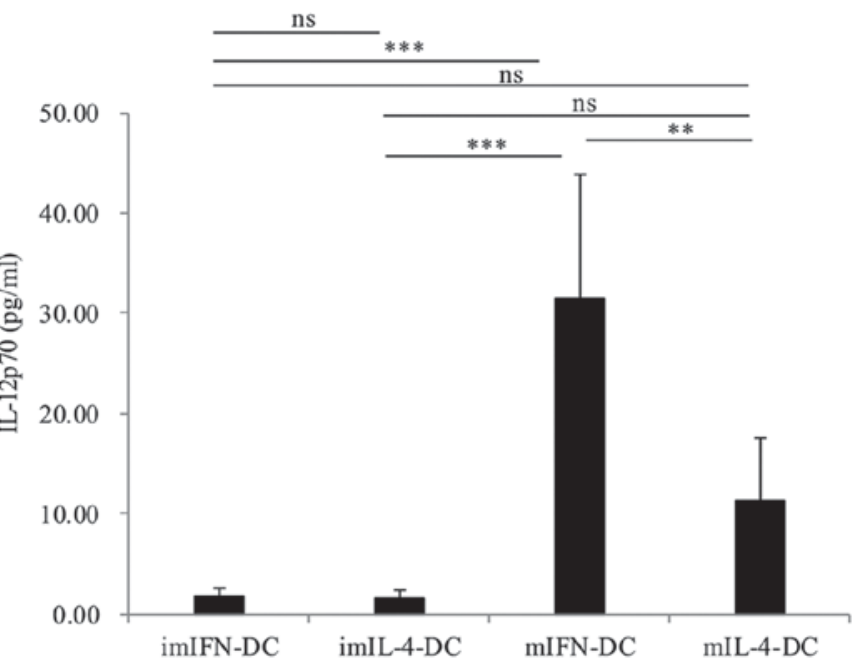

Figure 4. Cytokines produced by IFN-DC and IL-4-DC. IL-10 (A), IL-18 (B), IL-23 (C), IL-1 $\beta$ (D) and IL-12p70 (E) secreted by imIFN-DC, mIFN-DC, imIL-4-DC and mIL-4-DC were tested by ELISA. Results were represented as means \pm SEMs obtained from 3 independent experiments. Statistical analysis was performed with one-way ANOVA followed by a post-hoc test $\left({ }^{*} \mathrm{P}<0.05,{ }^{* *} \mathrm{P}<0.01,{ }^{* * *} \mathrm{P}<0.001\right)$. IFN, interferon; IL, interleukin; DCs, dendritic cells; m, mature; im, immature.

of the morphology, phenotype and function of these DCs still need to be explored. In this study, we showed that the morphologies of these two DCs were different in cell size, shape, spikes and cell internal structure. The phenotypes and secreted cytokines of IFN-DC and IL-4-DC were diverse. Furthermore, after loaded with CMV-pp65 protein, IFN-DC 
A
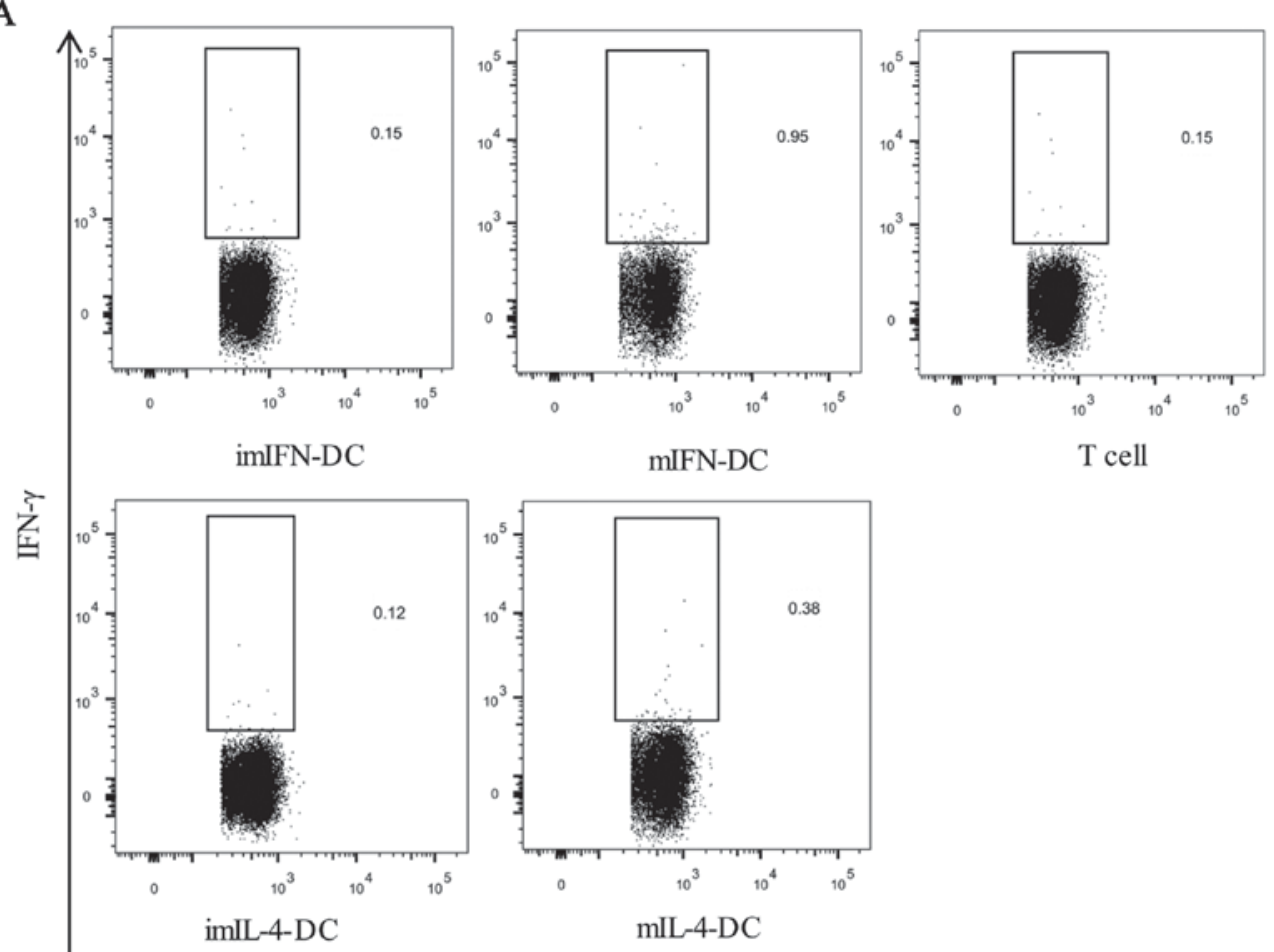

CD4

\section{B}
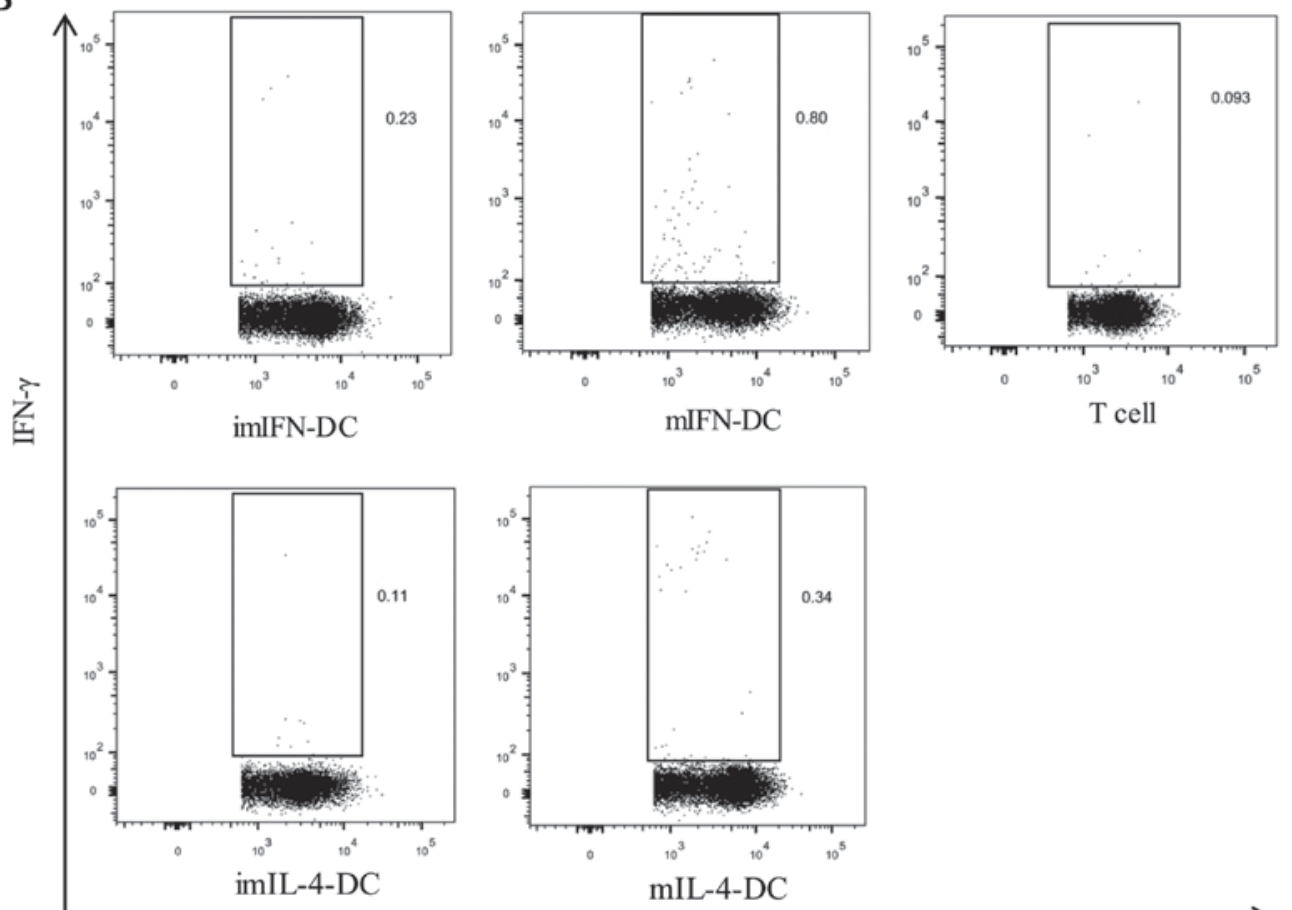

CD8

Figure 5. $\mathrm{CD}^{+}$and $\mathrm{CD}^{+} \mathrm{T}$ cells activation following exposure to the IFN-DC or IL-4-DC loaded with CMV-pp65 protein. The IFN-DC or IL-4-DC was loaded with CMV-pp65 protein. After $2 \mathrm{~h}$, autologous lymphocytes were added. Activation of T cells was assessed by determining the percentage of IFN $-\gamma^{+} \mathrm{CD} 4^{+}$cells (A) and IFN- $\gamma^{+} \mathrm{CD}^{+}$cells (B) detected by intracellular staining. The representative dot plots from one of the donors were shown. CD, cluster of differentiation; IFN, interferon; CMV, cytomegalovirus; IL, interleukin; DCs, dendritic cells; m, mature; im, immature.

could induce the activation of antigen specific $\mathrm{CD}^{+}$and $\mathrm{CD}^{+} \mathrm{T}$ cells more effectively than IL-4-DC.

Firstly, the scanning electron micoscopy results showed that mIFN-DC contained abundant organlles compared with
mIL-4-DC. In contrast, mIL-4-DC contained more vacuoles in the cells. This phenomenon was consistent with the results observed in BM-derived IL-4-DC from Lewis rats (29). Spadaro et al (10) used FITC conjugated OVA as antigen to 


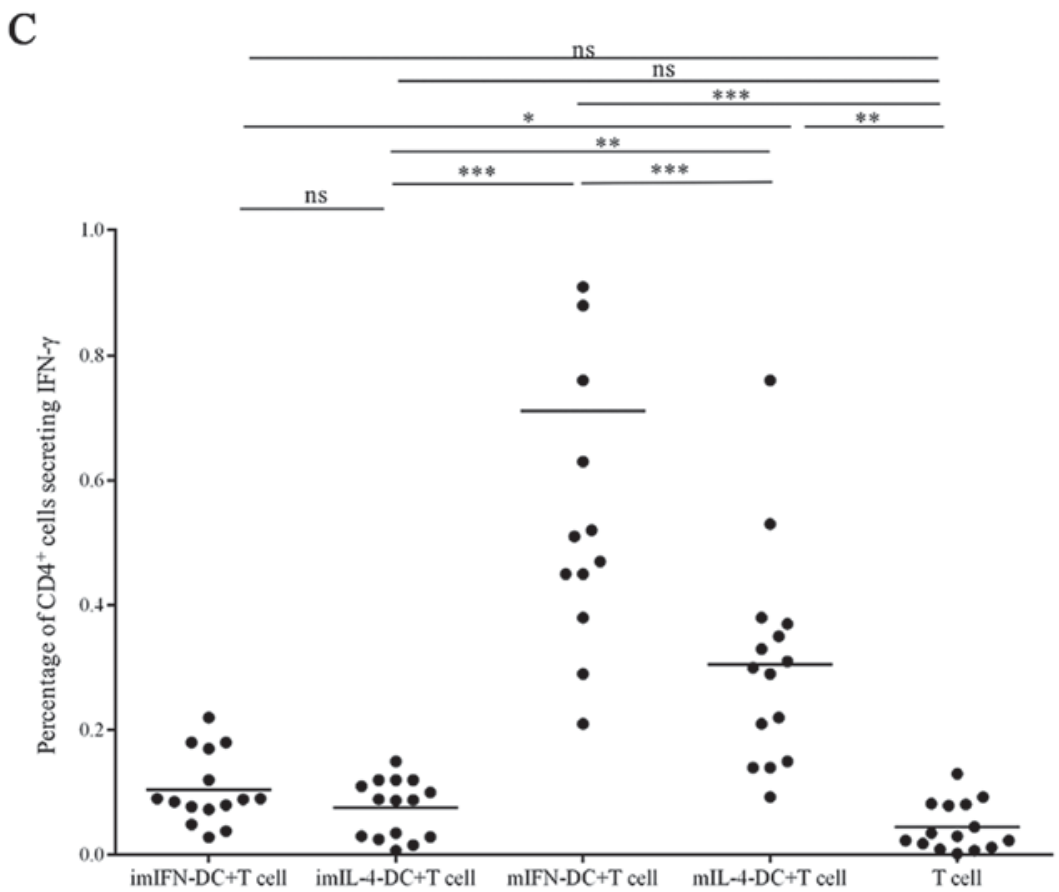

D

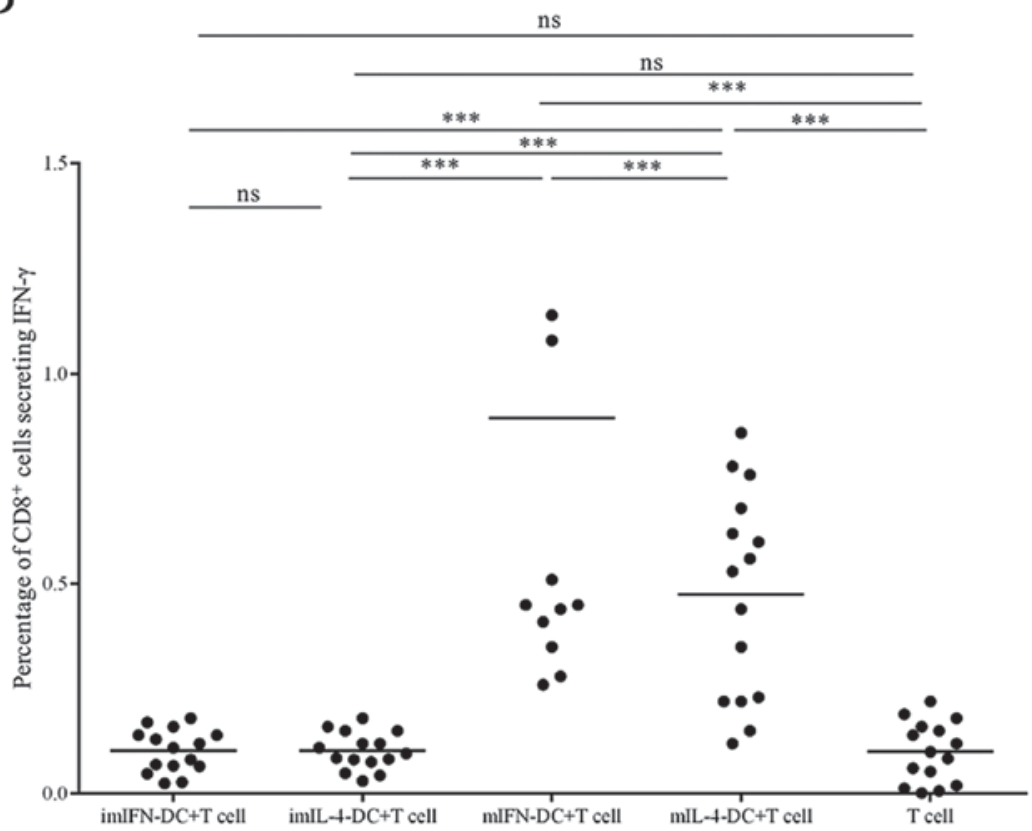

Figure 5. Continued. $\mathrm{CD} 4^{+}$and $\mathrm{CD} 8^{+} \mathrm{T}$ cells activation following exposure to the IFN-DC or IL-4-DC loaded with CMV-pp65 protein. $\mathrm{CD} 4^{+}(\mathrm{C})$ and $\mathrm{CD} 8^{+}$ $\mathrm{T}$ cell responses (D) from 15 donors were shown. Statistical analysis was performed with one-way ANOVA followed by a post-hoc test ("P<0.05, " $\mathrm{P}<0.01$, $\left.{ }_{* * * *} \mathrm{P}<0.001\right)$. CD, cluster of differentiation; IFN, interferon; CMV, cytomegalovirus; IL, interleukin; DCs, dendritic cells; m, mature; im, immature.

explore the transportation of soluble antigen in IFN-DC and IL-4-DC. The results showed that IFN-DC took more than $24 \mathrm{~h}$ to digest antigen while IL-4-DC needed $3 \mathrm{~h}$, which suggested that IL-4-DC possessed a more rapid degradation and endosomal acidification way than IFN-DC. According to our results, we speculated that the diversity of morphology of these two DCs might be the reason of the different route and mechanism of antigen entry of IFN-DC and IL-4-DC. However, the more details of the different endocytosis of these two DCs still need to be explored in future.
Then, we investigated the phenotypes of immature and mature IFN-DC and IL-4-DC. Of interest, there were no obvious difference for the expression of CD83 which was the mature marker of DCs between IFN-DC and IL-4-DC. This result was consistent with the study conducted by Carbonneil et al (30). However, some reports have revealed that the level of the expression of CD83 on the surface of imIFN-DC was higher compared to imIL-4-DC (31,32). Fujii et al (33) discovered that the costimulatory molecules CD80 and CD86 were necessary for the maturation of DCs. Our study showed that the CD80 expression 
had no obvious difference between these two mature DCs while the expression of CD86 by mIFN-DC was significantly higher than mIL-4-DC. Both CD80 and CD86 are prototypical members of the B7 co-signaling molecule family (34). Some studies showed that CLTA-4 was the preferential receptor for CD80 while CD28 bound mostly to CD86 $(35,36)$. And the most important function of CD28 is to induce the proliferation of $\mathrm{T}$ cells. Moreover, Lenschow and co-workers have found that CD86 could be expressed constitutively following T cell interaction with APCs (37). So we speculated that the different expression of CD80 and CD86 by IFN-DC and IL-4-DC might be one of the reasons explaining the higher antigen presenting ability of IFN-DC compared with IL-4-DC (38). There was no obvious difference for the expression of Class II MHC antigens HLA-DR and $\mathrm{mDC}$ marker CD11c between the immature IFN-DC and IL-4-DC. However, the expression of HLA-DR by mIFN-DC was higher than mIL-4-DC, while the CD11c expression was lower than mIL-4-DC. As HLA-DR is critical for DC to prime $\mathrm{CD}^{+}$cells, higher expression of HLA-DR by IFN-DC may be another reason to explain its stronger ability of presentation compared with IL-4-DC (39). The different expression of CD11c by these two DCs may reflect the different function of cell adhesion as CD11c is involved in the adhesion of cells (40).

Next, we analyzed the secretion of cytokines IL-18, IL-23, IL-12p70, IL-1 $\beta$ and IL-10 by IFN-DC and IL-4-DC. It is known that IL-18, IL-23, IL-12p70, IL-1 $\beta$ are the $\mathrm{T}$ helper cell 1 (Th1) pro-inflammatory cytokines and IL-10 is the Th2 anti-inflammatory cytokine $(38,41,42)$. And for cytokines IL-18, the most important biological activity is to induce T, $\mathrm{B}$ and NK cells to secret IFN- $\gamma$ (43). Although there was no difference for the secretion of IL-18 between imIFN-DC and imIL-4-DC, IL-18 secreted by mIFN-DC was significantly higher than mIL-4-DC. This result is consistent with the study of Mohamad which have showed that the pro-IL-18 protein existed in IFN-DC but not in IL-4-DC by western blot analysis (1). IL-23 and IL-12p70, as the members of cytokines IL-12 family, are the main stimulators of memory $\mathrm{T}$ cells proliferation and can induce the generation of pro-inflammatory Th1 and Th17 cells $(44,45)$. Moreover, IL-23 has been reported that it could synergize with IL-12 in promoting the production of cytokines by DC themselves (46). Our results showed that the secretions of IL-23 and IL-12p70 by both two types of mature DCs were increased dramatically compared with the immature DCs, which was consistent with the strong effect of mature DCs in activing T cells. As a member of the IL-1 family of cytokines, IL-1 $\beta$ is an important mediator of inflammatory response and also involved in proliferation, differentiation, and apoptosis of immune cells. In our results, IL-1 $\beta$ was secreted more effectively by IFN-DC than IL-4-DC, which might explain the stronger presenting function of IFN-DC.

At last we compared the function of presenting protein antigen between IFN-DC and IL-4-DC by detecting the IFN- $\gamma$ secretion by $\mathrm{T}$ cells. In accordance with our expectation, both of mature IFN-DC and IL-4-DC could present and cross-present CMV-pp65 protein more effectively than immature DCs, which was in consistent with the results of the cytokines secretion above. In consideration of the low percentage of the specific $\mathrm{T}$ cells for CMV-pp65 protein in PBMC, the IFN- $\gamma$ producing by $\mathrm{CD}^{+}$and $\mathrm{CD}^{+}$were relative low and the results were in line with the study by de Niet et al (47). On the other hand, we found that mIFN-DC was more effective in the priming of antigen specific $\mathrm{CD}^{+}$and $\mathrm{CD} 8^{+} \mathrm{T}$ cells than mIL-4-DC which had been reported by other studies $(1,19,48)$.

As a matter of fact, one of the most critical issues for DC-based vaccines is to identify the 'optimal' DCs subset. This study revealed the diversity between IFN-DC and IL-4-DC in the aspect of morphology, phenotypes and cytokines secretion. The data also suggested that IFN-DC could be more effective than IL-4-DC in priming and cross-priming T cells. Our results supported the view that the IFN-DC-based vaccine might be a more attractive and effective strategy for the immunotherapy.

\section{Acknowledgements}

This research was partially supported by grants from the National Natural Science Foundation of China (no. 81402559 to W.Y.), the Science and Technology Commission of Nanjing (no. 201605033 to W.Y.), the Project of Six Talent Peaks of Jiangsu Province (no. WSN-177 to W.Y.) and the Jiangsu Provincial Special Program of Medical Science (no. BL2014005 to Y.Y.).

\section{References}

1. Mohty M, Vialle-Castellano A, Nunes JA, Isnardon D, Olive D and Gaugler B: IFN-alpha skews monocyte differentiation into Toll-like receptor 7-expressing dendritic cells with potent functional activities. J Immunol 171: 3385-3393, 2003.

2. van Montfoort N, van der Aa E and Woltman AM: Understanding MHC class I presentation of viral antigens by human dendritic cells as a basis for rational design of therapeutic vaccines. Front Immunol 5: 182, 2014

3. Schreibelt G, Klinkenberg LJ, Cruz LJ, Tacken PJ, Tel J, Kreutz M, Adema GJ, Brown GD, Figdor CG and de Vries IJ: The C-type lectin receptor CLEC9A mediates antigen uptake and (cross-)presentation by human blood $\mathrm{BDCA}^{+}$myeloid dendritic cells. Blood 119: 2284-2292, 2012.

4. Sugita S, Kawazoe Y, Imai A, Usui Y, Iwakura Y, Isoda K, Ito M and Mochizuki M: Mature dendritic cell suppression by IL-1 receptor antagonist on retinal pigment epithelium cells. Invest Ophthalmol Vis Sci 54: 3240-3249, 2013.

5. Kim SW, Choi SM, Choo YS, Kim IK, Song BW and Kim HS: Flt3 ligand induces monocyte proliferation and enhances the function of monocyte-derived dendritic cells in vitro. J Cell Physiol 230: 1740-1749, 2015.

6. Gabriele L, Borghi P, Rozera C, Sestili P, Andreotti M, Guarini A, Montefusco E, Foà R and Belardelli F: IFN-alpha promotes the rapid differentiation of monocytes from patients with chronic myeloid leukemia into activated dendritic cells tuned to undergo full maturation after LPS treatment. Blood 103: 980-987, 2004.

7. Paquette RL, Hsu NC, Kiertscher SM, Park AN, Tran L, Roth MD and Glaspy JA: Interferon-alpha and granulocyte-macrophage colony-stimulating factor differentiate peripheral blood monocytes into potent antigen-presenting cells. J Leukoc Biol 64: 358-367, 1998.

8. Lapenta C, Santini SM, Logozzi M, Spada M, Andreotti M, Di Pucchio T, Parlato S and Belardelli F: Potent immune response against HIV-1 and protection from virus challenge in hu-PBL-SCID mice immunized with inactivated virus-pulsed dendritic cells generated in the presence of IFN-alpha. J Exp Med 198: 361-367, 2003.

9. Rizza P, Moretti F, Capone I and Belardelli F: Role of type I interferon in inducing a protective immune response: Perspectives for clinical applications. Cytokine Growth Factor Rev 26: 195-201, 2015.

10. Spadaro F, Lapenta C, Donati S, Abalsamo L, Barnaba V, Belardelli F, Santini SM and Ferrantini M: IFN-alpha enhances cross-presentation in human dendritic cells by modulating antigen survival, endocytic routing, and processing. Blood 119: 1407-1417, 2012. 
11. Carbonneil C, Aouba A, Burgard M, Cardinaud S, Rouzioux C, Langlade-Demoyen P and Weiss L: Dendritic cells generated in the presence of granulocyte-macrophage colony-stimulating factor and IFN-alpha are potent inducers of HIV-specific CD 8 T cells. AIDS 17: 1731-1740, 2003.

12. Lapenta C, Santini SM, Spada M, Donati S, Urbani F, Accapezzato D, Franceschini D, Andreotti M, Barnaba V and Belardelli F: IFN-alpha-conditioned dendritic cells are highly efficient in inducing cross-priming CD8(+) T cells against exogenous viral antigens. Eur J Immunol 36: 2046-2060, 2006.

13. Pilon C, Levast B, Meurens F, Le Vern Y, Kerboeuf D, Salmon H, Velge-Roussel F, Lebranchu Y and Baron C: CD40 engagement strongly induces CD25 expression on porcine dendritic cells and polarizes the $\mathrm{T}$ cell immune response toward Th1. Mol Immunol 46: 437-447, 2009.

14. Korthals M, Safaian N, Kronenwett R, Maihöfer D, Schott M, Papewalis C, Diaz Blanco E, Winter M, Czibere A, Haas R, et al: Monocyte derived dendritic cells generated by IFN-alpha acquire mature dendritic and natural killer cell properties as shown by gene expression analysis. J Transl Med 5: 46, 2007.

15. McRae BL, Nagai T, Semnani RT, van Seventer JM and van Seventer GA: Interferon-alpha and -beta inhibit the in vitro differentiation of immunocompetent human dendritic cells from CD14(+) precursors. Blood 96: 210-217, 2000.

16. Lapenta C, Donati S, Spadaro F, Castaldo P, Belardelli F, Cox MC and Santini SM: NK cell activation in the antitumor response induced by IFN- $\alpha$ dendritic cells loaded with apoptotic cells from follicular lymphoma patients. J Immunol 197: 795-806, 2016.

17. Chabot V, Martin L, Meley D, Sensebé L, Baron C, Lebranchu Y, Dehaut $\mathrm{F}$ and Velge-Roussel F: Unexpected impairment of TNF- $\alpha$-induced maturation of human dendritic cells in vitro by IL-4. J Transl Med 14: 93, 2016.

18. Farkas A, Tonel G and Nestle FO: Interferon-alpha and viral triggers promote functional maturation of human monocyte-derived dendritic cells. Br J Dermatol 158: 921-929, 2008.

19. Santini SM, Lapenta C, Donati S, Spadaro F, Belardelli F and Ferrantini M: Interferon- $\alpha$-conditioned human monocytes combine a Th1-orienting attitude with the induction of autologous Th17 responses: Role of IL-23 and IL-12. PLoS One 6: e17364, 2011.

20. Trinchieri G: Interleukin-12 and the regulation of innate resistance and adaptive immunity. Nat Rev Immunol 3: 133-146, 2003.

21. Askenase MH, Han SJ, Byrd AL, Morais da Fonseca D, Bouladoux N, Wilhelm C, Konkel JE, Hand TW, Lacerda-Queiroz N, Su XZ, et al: Bone-marrow-resident NK cells prime monocytes for regulatory function during infection. Immunity 42: 1130-1142, 2015.

22. Childs BG, Baker DJ, Wijshake T, Conover CA, Campisi J and van Deursen JM: Senescent intimal foam cells are deleterious at all stages of atherosclerosis. Science 354: 472-477, 2016.

23. Oehler L, Majdic O, Pickl WF, Stöck1 J, Riedl E, Drach J, Rappersberger K, Geissler K and Knapp W: Neutrophil granulocyte-committed cells can be driven to acquire dendritic cell characteristics. J Exp Med 187: 1019-1028, 1998

24. Farkas A and Kemény L: Interferon- $\alpha$ in the generation of monocyte-derived dendritic cells: recent advances and implications for dermatology. Br J Dermatol 165: 247-254, 2011.

25. Wang S, Sun X, Zhou H, Zhu Z, Zhao W and Zhu C: Interleukin- 4 affects the mature phenotype and function of rat bone marrow-derived dendritic cells. Mol Med Rep 12: 233-237, 2015.

26. Gessani S, Conti L, Del Cornò M and Belardelli F: Type I interferons as regulators of human antigen presenting cell functions. Toxins (Basel) 6: 1696-1723, 2014.

27. Guenova E, Skabytska Y, Hoetzenecker W, Weindl G, Sauer K Tham M, Kim KW, Park JH, Seo JH, Ignatova D, et al: IL-4 abrogates $\mathrm{T}(\mathrm{H}) 17$ cell-mediated inflammation by selective silencing of IL-23 in antigen-presenting cells. Proc Natl Acad Sci USA 112: 2163-2168, 2015.

28. Okada S, Han S, Patel ES, Yang LJ and Chang LJ: STAT3 signaling contributes to the high effector activities of interleukin-15-derived dendritic cells. Immunol Cell Biol 93: 461-471, 2015.

29. Taieb A, Breitinger JJ, Unadkat JV, Shufesky WJ, Morelli AE, Thomson AW, Lee WP and Feili-Hariri M: Intrinsic ability of GM+IL-4 but not Flt3L-induced rat dendritic cells to promote allogeneic $\mathrm{T}$ cell hyporesponsiveness. Clin Immunol 123: 176-189, 2007
30. Carbonneil C, Saidi H, Donkova-Petrini V and Weiss L: Dendritic cells generated in the presence of interferon-alpha stimulate allogeneic $\mathrm{CD}^{+} \mathrm{T}$-cell proliferation: Modulation by autocrine IL-10, enhanced T-cell apoptosis and T regulatory type 1 cells Int Immunol 16: 1037-1052, 2004.

31. Della Bella S, Nicola S, Riva A, Biasin M,Clerici M and Villa ML: Functional repertoire of dendritic cells generated in granulocyte macrophage-colony stimulating factor and interferon-alpha. J Leukoc Biol 75: 106-116, 2004

32. Papewalis C, Jacobs B, Wuttke M, Ullrich E, Baehring T, Fenk R, Willenberg HS, Schinner S, Cohnen M, Seissler J, et al: IFN-alpha skews monocytes into CD56 ${ }^{+}$-expressing dendritic cells with potent functional activities in vitro and in vivo. J Immunol 180: 1462-1470, 2008

33. Fujii S, Liu K, Smith C, Bonito AJ and Steinman RM: The linkage of innate to adaptive immunity via maturing dendritic cells in vivo requires $\mathrm{CD} 40$ ligation in addition to antigen presentation and CD80/86 costimulation. J Exp Med 199: 1607-1618, 2004.

34. Freeman GJ, Gribben JG, Boussiotis VA, Ng JW, Restivo VA Jr, Lombard LA, Gray GS and Nadler LM: Cloning of B7-2: A CTLA-4 counter-receptor that costimulates human T cell proliferation. Science 262: 909-911, 1993.

35. Evans EJ, Esnouf RM, Manso-Sancho R, Gilbert RJ, James JR, Yu C, Fennelly JA, Vowles C, Hanke T, Walse B, et al: Crystal structure of a soluble CD28-Fab complex. Nat Immunol 6: 271-279, 2005

36. Pentcheva-Hoang T, Egen JG, Wojnoonski K and Allison JP: B7-1 and B7-2 selectively recruit CTLA-4 and CD28 to the immunological synapse. Immunity 21: 401-413, 2004

37. Lenschow DJ, Walunas TL and Bluestone JA: CD28/B7 system of T cell costimulation. Annu Rev Immunol 14: 233-258, 1996

38. Leplina OY, Tyrinova TV, Tikhonova MA, Ostanin AA and Chernykh ER: Interferon alpha induces generation of semi-mature dendritic cells with high pro-inflammatory and cytotoxic potential. Cytokine 71: 1-7, 2015.

39. van Lummel M, van Veelen PA, de Ru AH, Janssen GM, Pool J, Laban S, Joosten AM, Nikolic T, Drijf hout JW, Mearin ML, et al: Dendritic cells guide islet autoimmunity through a restricted and uniquely processed peptidome presented by high-risk HLA-DR. J Immunol 196: 3253-3263, 2016.

40. Foster GA, Xu L, Chidambaram AA, Soderberg SR, Armstrong EJ, Wu H and Simon SI: CD11c/CD18 signals very late antigen- 4 activation to initiate foamy monocyte recruitment during the onset of hypercholesterolemia. J Immunol 195 5380-5392, 2015.

41. Arnold IC, Mathisen S, Schulthess J, Danne C, Hegazy AN and Powrie F: CD11c(+) monocyte/macrophages promote chronic Helicobacter hepaticus-induced intestinal inflammation through the production of IL-23. Mucosal Immunol 9: 352-363, 2016.

42. Banchereau J, Pascual V and O'Garra A: From IL-2 to IL-37: The expanding spectrum of anti-inflammatory cytokines. Nat Immunol 13: 925-931, 2012.

43. Yoshimoto T, Takeda K, Tanaka T, Ohkusu K, Kashiwamura S, Okamura H, Akira S and Nakanishi K: IL-12 up-regulates IL-18 receptor expression on T cells, Th1 cells, and B cells: Synergism with IL-18 for IFN-gamma production. J Immunol 161 3400-3407, 1998

44. Behzadi P, Behzadi E and Ranjbar R: IL-12 family cytokines: General characteristics, pathogenic microorganisms, receptors and signalling pathways. Acta Microbiol Immunol Hung 63: $1-25,2016$.

45. Vignali DA and Kuchroo VK: IL-12 family cytokines: Immunological playmakers. Nat Immunol 13: 722-728, 2012.

46. Belladonna ML, Renauld JC, Bianchi R, Vacca C, Fallarino F, Orabona C, Fioretti MC, Grohmann U and Puccetti P: IL-23 and IL-12 have overlapping, but distinct, effects on murine dendritic cells. J Immunol 168: 5448-5454, 2002.

47. de Niet A, Stelma F, Jansen L, Sinnige MJ, Remmerswaal EB, Takkenberg RB, Kootstra NA, Reesink HW, van Lier RA and van Leeuwen EM: Restoration of T cell function in chronic hepatitis B patients upon treatment with interferon based combination therapy. J Hepatol 64: 539-546, 2016.

48. Aarntzen EH, De Vries IJ,Lesterhuis WJ, Schuurhuis D, Jacobs JF, Bol K, Schreibelt G, Mus R, De Wilt JH, Haanen JB, et al: Targeting CD4(+) T-helper cells improves the induction of antitumor responses in dendritic cell-based vaccination. Cancer Res 73: 19-29, 2013 